\title{
General Psychiatry Client-level predictors of treatment engagement, outcome and dropout: moving beyond demographics
}

Soo-jeong Youn (D) , ${ }^{1,2}$ Margaret-Anne Mackintosh, ${ }^{3}$ Shannon Wiltsey Stirman, ${ }^{4,5}$ Kaylie A Patrick, ${ }^{1}$ Yesenia Aguilar Silvan, ${ }^{1}$ Anna D Bartuska, ${ }^{1}$ Derri L Shtasel,,${ }^{1,2}$ Luana Marques ${ }^{1,2}$
To cite: Youn S, Mackintosh MA, Wiltsey Stirman S, et al. Client-level predictors of treatment engagement, outcome and dropout: moving beyond demographics. General Psychiatry 2019;32:e100153. doi:10.1136/ gpsych-2019-100153

DLS and LM are joint senior authors.

Received 28 September 2019

Revised 21 October 2019

Accepted 27 October 2019
Check for updates

(C) Author(s) (or their employer(s)) 2019. Re-use permitted under CC BY-NC. No commercial re-use. See rights and permissions. Published by BMJ.

${ }^{1}$ Deparment of Psychiatry, Massachusetts General Hospital, Boston, Massachusetts, USA ${ }^{2}$ Harvard Medical School, Boston, Massachusetts, USA ${ }^{3}$ Stat Craft, Brentwood, California, USA

${ }^{4}$ Dissemination and Training Division, National Center for PTSD, VA Palo Alto Health Care System, Menlo Park, California, USA

${ }^{5}$ Department of Psychiatry and Behavioral Sciences, Stanford University School of Medicine, Stanford, California, USA

Correspondence to Dr. Soo-jeong Youn; soojeong.youn@mgh.harvard. edu

\section{ABSTRACT}

Background Despite the availability of evidence-based treatments for posttraumatic stress disorder (PTSD), significant heterogeneity in the effectiveness of PTSD treatment persists, especially in community settings. Client demographics used to understand this variability in treatment outcome and dropout have yielded mixed results. Despite increasing evidence for the importance of attending to treatment engagement in community settings, few studies have explored client-level predictors.

Aim The purpose of this study is to explore client-level predictors of treatment outcome and dropout beyond client demographics, and to identify client-level predictors of treatment engagement in community settings.

Method Secondary data analysis was conducted with data collected as part of an implementation-effectiveness hybrid study of cognitive processing therapy (CPT) for PTSD in a diverse community health centre. Providers $(n=19)$ treated $(n=52)$ clients as part of their routine clinical care. Non-demographic client-level predictors included barriers to treatment, quality of life, session-level language and employment history assessed at baseline. Treatment engagement included number of weeks in the study, number of sessions with repeated CPT content, number of unique CPT sessions attended, frequency of session attendance and consistency of session attendance. Results Results showed language as a significant predictor of treatment engagement. There were significant differences between Spanish and English-speaking clients, with the former having a tendency to repeat more session content than the latter $(\beta=1.4$ sessions, $p=0.003$ ), and also less likely to attend treatment frequently $(r=0.62, p=0.009)$ and consistently $(r=0.57$, $p=0.027$ ) if high logistical and financial barriers were endorsed. Irrespective of language, clients who reported high quality of life at baseline were less likely to repeat CPT session content $(\beta=-0.3, p=0.04)$, and those with increased baseline barriers to treatment had deceleration in PTSD symptom improvement over time ( $\beta=-0.62$, $p<0.05)$. In terms of treatment engagement moderators impacting treatment outcome, clients who repeated more session content were more likely to complete treatment $(\mathrm{OR}=1.84, p=0.037)$.

Conclusion Identification of client-level predictors of treatment engagement, outcome and dropout is essential to optimise treatment, particularly in community settings.

\section{INTRODUCTION}

Posttraumatic stress disorder (PTSD) is a chronic and disabling psychological disorder that leads to significant impairment in interpersonal and work functioning. ${ }^{1}$ Despite the availability of several evidence-based treatments for PTSD the effectiveness of these treatments has yielded mixed results, especially in community settings (eg, ref 2). To address this heterogeneity in outcomes, there has been an increased focus on 'personalized medicine', with an emphasis on identifying predictors and treatment moderators that can help differentiate and understand differing treatment outcomes for individuals. ${ }^{3}$ This identification of pretreatment and moderating client characteristics that can predict differential responses to treatment is crucial as they can be leveraged to optimise treatment, especially for those with poorer outcomes. ${ }^{4}$

Several studies have focused on identifying client-level demographic predictors of different types of treatment outcome for PTSD, but with mixed results. For example, some studies have found that fixed demographic characteristics, such as sex, age, education level and marital status, did not predict treatment outcome (eg, ref 5) whereas others found significant treatment differential outcomes (eg, ref 6). Thus, the exploration of predictors of treatment response in PTSD has yielded mixed results. A similar pattern is present when identifying predictors of treatment dropout. A recent meta-analysis by Swift and Greenberg showed that despite client demographic variables having been explored most frequently as predictors, few led to consistent results related to dropout. ${ }^{7}$

The inconsistency in the pretreatment client-level predictors for both PTSD symptom improvement and dropout highlights the importance of looking at additional 
variables that may help understand the differential effectiveness of PTSD treatment and high dropout rates. ${ }^{2}$ For example, treatment language could be of potential significance for predicting treatment outcome and/or dropout. Previous research has shown that treatment language impacts the actual delivery of treatment, with clients seen in community settings often reporting difficulties in treatment related to language barriers. ${ }^{8}$ Furthermore, there is growing evidence for the need and importance of adapting evidence-based treatments (EBTs), such as cognitive processing therapy (CPT) ${ }^{9}$ to address these language-related treatment limitations when delivered in these settings (eg, ref 10).

Client's barriers to treatment seeking could be another significant client-level predictor of PTSD treatment outcome and dropout. For example, different types of barriers to seeking treatment, such as stigma, logistical and financial concerns, and attitudes towards treatment, have been shown to impact clients' treatment utilisation (eg, ref 11), and there is preliminary evidence suggesting that they may even impact treatment outcomes. For example, shame and guilt at pretreatment have been shown to lead to less decrease in PTSD symptoms over the course of therapy (eg, ref 12), whereas stigma, logistical and financial concerns, and negative attitudes towards treatment increased the likelihood of dropout from treatment (eg, ref 13).

Previous studies also suggest exploring baseline PTSD severity as a significant predictor for treatment outcome and dropout. Baseline PTSD severity has been associated with poorer quality of life and there is evidence to support the synchronous change in PTSD symptoms, quality of life and employment gains during treatment. ${ }^{14}$ The few studies that have started to understand the relationship between baseline PTSD severity and treatment outcome have yielded mixed results (eg, ref 5 15). Accordingly, it is important to assess whether these additional client-level characteristic variables may predict treatment outcome and dropout in PTSD.

In addition to exploring more reliable predictors of treatment outcome, variables that predict treatment engagement in community settings are also important. A recent study by Gutner et al found a high degree of variability in clients' frequency and consistency of treatment attendance in a trauma clinic that served the community, and their results showed that more frequent and consistent session attendance was associated with greater PTSD symptom reduction, highlighting the importance of further exploring these treatment moderators among diverse samples of trauma survivors. ${ }^{16}$ Furthermore, Imel et al found that greater number of sessions attended predicted client's treatment dropout in PTSD. ${ }^{17}$ Despite the importance of attendance as a treatment moderator, few studies to date have explored client-level predictors of attendance and other types of assessments of treatment engagement. For example, stigma, but not clients' attitudes towards treatment, has been shown to be significantly related to number of sessions received. ${ }^{18}$ Lower quality of life scores have been shown to be associated with lower treatment attendance in clients with PTSD. ${ }^{19}$ Thus, it is imperative to explore client-level predictors that impact the various ways that clients seen in community settings engage in treatment.

The primary aim of this study is to build on the existing literature with two goals: (1) explore additional clientlevel predictors of treatment outcome and dropout in PTSD treatment that extend beyond client demographics, and (2) identify client-level predictors of treatment engagement. The results of the present study would aid researchers and clinicians in optimising treatment for PTSD by helping identify clients with differing treatment outcomes.

\section{METHOD \\ Participants \\ Providers}

Mental health providers working in a diverse community health centre participated in the study. Providers were eligible to participate in the study if they were able to receive the CPT training in English, they provided treatment to at least one client with a primary diagnosis of PTSD in either English and/or Spanish, and agreed to complete the study procedures, including self-report measures, and participate in CPT consultation for 6 months.

\section{Clients}

Clients were eligible to participate if they were at least 18 years old, had a primary diagnosis of PTSD as indicated by their medical record and/or Posttraumatic Stress Disorder Checklist-Specific version $\left(\right.$ PCL-S ${ }^{20}$ score above the clinical cut-off $(>36),{ }^{21}$ agreed to have their sessions audio recorded for research purposes and were able to participate in therapy in English or Spanish. Clients who were acutely suicidal or homicidal, required hospitalisation, had an unstable psychiatric medication regimen, evidenced current psychosis or mania, had a current primary diagnosis of substance dependence, were prescribed benzodiazepines, or reported concurrent cognitive-behavioural therapy or previous CPT treatment were excluded from the study (see figure 1 for study enrolment). This paper represents secondary data analyses of 52 clients who attended at least three CPT sessions.

\section{Measures}

\section{Baseline demographic information}

Clients and providers completed a demographic form at baseline, including questions about their gender, age, race/ethnicity, marital status, educational level, income and employment history.

\section{PTSD symptoms}

The PCL-S is a widely used 17-item self-report measure of Diagnostic and Statistical Manual of Mental DisordersFourth Edition criteria of PTSD symptoms. ${ }^{20}$ Clients 
Clients assessed for study eligibility $(n=98):>=18$ years old, had a primary diagnosis of PTSD in their medical record and/or Posttraumatic Symptom Checklist-Specific Version (PCL-S) score $>$ 36, agreed to have their sessions audio recorded for research purposes, and able to participate in therapy in English or Spanish.

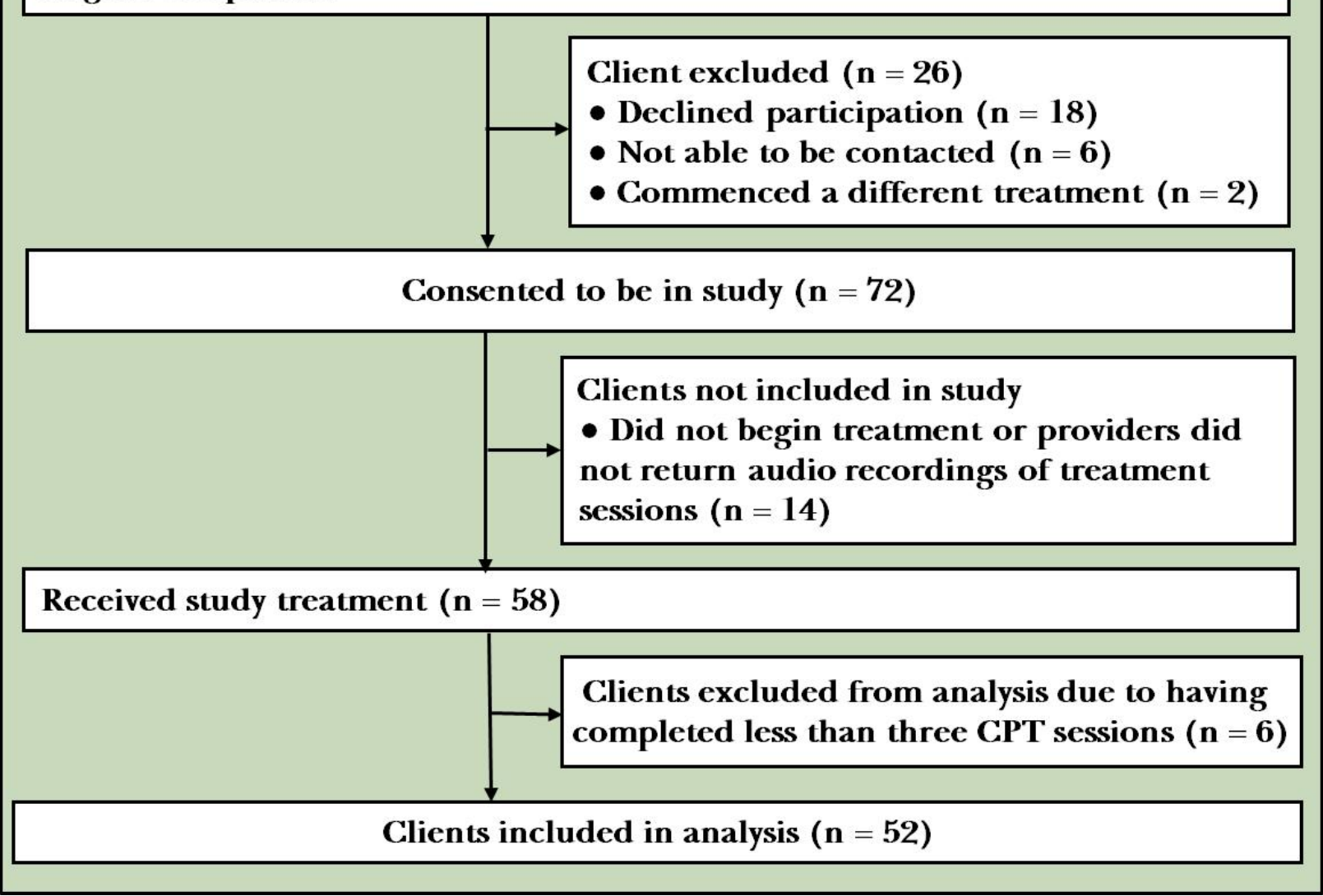

Figure 1 Client study enrolment. CPT, cognitive processing therapy; PTSD, post-traumatic stress disorder.

are asked to rate how much they are bothered by each PTSD symptom in the past week using a 5-point Likert scale $(1=$ Not at all, $5=$ Extremely $)$ to generate a total score, ranging from 17 to 85 , with higher scores indicating greater symptom severity. The PCL-S has been shown to have good internal consistency $(\alpha>0.75)$, test-retest reliability $(r=0.87)$ and high convergent validity $(r=0.93)$ and discriminant validity with measures of PTSD than with measures assessing depression, other psychopathology and physical pain. ${ }^{21}$ Cronbach's $\alpha$ was 0.87 for the English version, 0.85 for the Spanish version and 0.87 for both versions combined at baseline.

\section{Depressive symptoms}

Clients' depressive symptoms were assessed with the Patient Health Questionnaire (PHQ-9), ${ }^{22}$ a widely used 9-item self-report measure. Clients note how frequently they have been bothered by symptoms of depression over the last 2 weeks on a 4-point Likert scale $(0=$ Not at all, $4=$ Nearly every day), generating a total score ranging from 0 to 27. The PHQ-9 has been shown to have strong internal consistency (Cronbach's $\alpha=0.89$ ), test-retest reliability $(r=0.84)$ and construct validity. ${ }^{22}$ The publicly available Spanish translation of the PHQ-9 was used in this study, and it has been validated in Latino populations, and found to be an acceptable, culturally appropriate and feasible measure to screen for depressive symptoms in Spanish-speaking populations. ${ }^{23}$ It has demonstrated strong internal consistency (Cronbach's $\alpha=0.84$ ) and construct validity. ${ }^{24}$ For the current study, Cronbach's $\alpha$ was 0.82 for the English version, 0.91 for the Spanish version and 0.84 for both versions combined at baseline.

\section{Barriers to treatment}

The Barriers to Treatment Questionnaire (BTQ) is a 24-item self-report measure that assesses clients' perceived barriers that may have prevented them from seeking or accessing treatment for mental health concerns in the past year. ${ }^{25}$ The BTQ assesses three different domains: (1) logistical and financial barriers (BTQ-L/F subscale); (2) stigma, shame and discrimination barriers (BTQ-S/D subscale); and (3) treatment perception and satisfaction barriers (BTQ-P/S subscale). Clients are asked to indicate the extent to which these barriers impacted their decision 
to delay or avoid mental health treatment seeking in the past year, using a 5-point Likert scale ranging from $0=$ Not at all to $4=$ Extremely. A composite score is calculated for each domain, with higher scores indicating more barriers. The first domain, BTQ-L/F, includes seven items that assess barriers related to the cost of treatment, health insurance, time constraints and transportation barriers, with a composite score ranging from 0 to 28 . The BTQ$\mathrm{S} / \mathrm{D}$ includes seven items that address barriers such as feelings of shame about one's mental health needs, fear of being judged and beliefs that one can manage mental health problems on one's own, with a composite score ranging from 0 to 24 . The $\mathrm{BTQ}-\mathrm{P} / \mathrm{S}$ includes three items that assess barriers such as perceived ineffectiveness of treatment and satisfaction with available treatments, with a composite ranging from 0 to 12 . The Spanish version of the BTQ used in the present study was translated by a trained and certified medical translation specialist from the Massachusetts General Hospital. In the present study, Cronbach's $\alpha$ for the BTQ-L/F was 0.55 for the English version, 0.53 for the Spanish version and 0.53 for both versions combined. Cronbach's $\alpha$ for the BTQ-S/D was 0.85 for the English version, 0.87 for the Spanish version and 0.87 for both versions combined at baseline. Cronbach's $\alpha$ for the BTQ-P/S was 0.64 for the English version, 0.51 for the Spanish version and 0.60 for both versions combined at baseline. Inspection of the item-level data for the BTQ-L/F subscale suggests that in this study most clients did not report many logistical or financial barriers to access treatment. For example, nine patients reported no barriers and five reported one barrier each, comprising $27 \%$ of the sample. Psychometrically, this situation lowers the between-item correlations for the scale and results in the low Cronbach's alphas observed.

\section{Quality of life}

The Multicultural Quality of Life Index (MQLI) ${ }^{26}$ is an adapted 10-item self-report version of the 32-item Quality of Life Index. ${ }^{27}$ The MQLI was developed to be used in a variety of settings and relevant to diverse cultural backgrounds. The measure asked respondents to rate their current life and health across 10 dimensions, using a Likert scale ranging from $1=$ Poorto $10=$ Excellent, to yield a total score, with higher scores representing a higher reported quality of life. The MQLI has been shown to have high internal consistency (Cronbach's $\alpha=0.92$ ) and test-retest reliability $(0.87) .{ }^{26}$ The available validated Spanish version of the MQLI was used for this study, which has been shown to have high discriminant validity, high internal consistency (Cronbach's $\alpha=0.88$ ) and test-retest reliability (0.94) ${ }^{28}$ For the current sample, Cronbach's $\alpha$ for the MQLI was 0.87 for the English version, 0.95 for the Spanish version and 0.91 for both versions combined at baseline.

\section{Treatment outcome and treatment engagement}

Six measures related to treatment participation and timing of sessions were evaluated: (1) number of weeks in study, (2) number of sessions with repeated CPT content (ie, number of sessions that repeated CPT content/interventions that were already covered during a previous session), (3) dose of CPT (ie, number of unique CPT sessions attended expressed as a percentage out of the possible 12 sessions), (4) frequency of sessions (ie, mean number of days between sessions ${ }^{16}$ ), (5) consistency of sessions (ie, SD of the number of days between sessions ${ }^{16}$ ), and (6) a binary outcome indicating whether a client completed treatment or not. In this study, treatment completion was defined as having completed 12 CPT sessions or as determined by the treating clinician's clinical judgement.

\section{Procedure}

Providers were trained in CPT as part of a National Institute of Mental Health-funded (NIMH K23MH096029-01A1) implementation-effectivenesshybrid pilot study of CPT for PTSD (for detaileddescription of the study design, please see $\left.\operatorname{ref}^{29}\right)$.Briefly, the study evaluated the feasibility andacceptability of adapting the CPT manual to be linguistically, culturally and contextually appropriatefor a low-income, diverse community population. The adapted manual was implemented and pilottested in a diverse community health centre withproviders and clients in both English and Spanish.The results showed that the adapted manual isan effective and appropriate intervention for thispopulation (masked for publication; masked forpublication).

CPT is a 12-session manualised treatment protocol designed specifically for PTSD, with a focus on identifying and challenging client's 'stuck points', or areas of conflicting beliefs and assumptions that maintain the symptoms of PTSD. Each session includes session-specific goals and prescribed set of interventions and content material that the provider and the client discuss and use as the basis for assigning homework for the next session.

Providers identified and invited eligible clients to participate in the study as part of routine clinical care. Interested clients met with a research staff member to provide informed consent. Participants completed all measures at baseline, prior to the first clinical treatment visit, and completed the PCL-S and PHQ-9 weekly.

\section{Data analytic plan}

Missing data

Most clients (96.2\%) were missing data on one or more variables as is common in studies conducted in clinically representative conditions. Missing data rates for PCL-S at each session ranged from $13.5 \%$ at session 1 to $53.8 \%$ at session 9 with an average of $29.8 \%$ per session. Similar missing data rates were observed for PHQ-9 scores with the lowest rate at baseline $(13.5 \%)$ and the highest at session $9(57.7 \%)$ with an average of $33.1 \%$ per session. Missing data were addressed using an inclusive analysis strategy to identify auxiliary variables that were included in the model when generating 100 multiple imputation data sets (see ref 30). The large number of data sets was 
selected to stabilise the imputed values in the analyses stage, which is important in estimating treatment differences with longitudinal data. ${ }^{31}$ Preliminary analyses identified demographic factors related to the study outcomes using t-tests. Imputation of missing data and latent growth curve modelling was conducted using Mplus (V.8) ${ }^{32}$ and other inferential tests and data management were conducted using SPSS (V.25.0). ${ }^{33}$

\section{Research aim 1}

The first research goal was to explore client-level predictors of treatment-related variables beyond client demographics. The predictors were client baseline scores from the three BTQ subscales $(\mathrm{L} / \mathrm{F}, \mathrm{S} / \mathrm{D}, \mathrm{P} / \mathrm{S})$, the total MQLI score, session language $(0=$ English, $1=$ Spanish $)$ and employment history (1=virtuallyall of the time, $0=$ less than all the time). Multiple linear regression for continuous dependent measures and binary logistic regression for nominal dependent variables were used to determine the impact of client variables on treatment-related variables. Predictor variables were entered as a single block. Unstandardised regression coefficient with their 95\% CIs is reported for linear regressions and ORs with their 95\% CI are reported for logistic regression results. Interaction terms for session language and scores of the BTQ subscales and MQLI were explored. Preliminary analyses suggested that variables related to clients' session attendance were differentially influenced by session language and BTQ-L/F scores, and, thus, their interaction was included in all models. Multilevel modelling was used to estimate the variation in outcomes related to patients being nested within therapists. Estimated clinician effects accounted for less than $5 \%$ of the variance. Per the recommendation in Heck et al, ${ }^{34}$ that multilevel modelling was not required in these situations and given the additional complexity of multilevel models given the small sample size, we did not adjust for patients nested within therapists in our analyses. Finally, due to the limited sample size, we did not adjust the significance values to address family-wise error.

\section{Research aim 2}

The second research goal focused on identifying whether the significant predictors from the first set of analyses, and the treatment engagement-related variables modified three treatment outcomes: (1) PTSD symptom trajectories (PCL-S), (2) depressive symptom trajectories (PHQ-9), and (3) treatment completion. Though underpowered to identify small to medium-effect sizes, we used latent growth curve models to explore whether the client-level predictors strongly influenced symptom trajectories in PCL-S and PHQ-9 scores for the first nine treatment sessions. A cut-off of nine sessions was selected to more closely adhere to patterns of treatment attendance. In the current sample, clients attended an average of 7.5 CPT sessions ( $\mathrm{SD}=3.46$ ). For each model, we estimated random effects representing the intercept, linear slope and quadratic change in symptoms over time and

\begin{tabular}{|c|c|}
\hline & n (\%) \\
\hline Gender-female & 35 (67.3) \\
\hline \multicolumn{2}{|l|}{ Primary race* } \\
\hline Black or African-American & $2(3.8)$ \\
\hline Latino/Hispanic & $26(50.0)$ \\
\hline White & $19(36.5)$ \\
\hline Other or biracial & $4(7.7)$ \\
\hline \multicolumn{2}{|l|}{ Marital status ${ }^{*}$} \\
\hline Single & $21(40.4)$ \\
\hline Living with partner & $5(9.6)$ \\
\hline Married & $12(23.1)$ \\
\hline Divorced or separated & $12(23.1)$ \\
\hline \multicolumn{2}{|l|}{ Education* } \\
\hline Less than high school & $11(21.2)$ \\
\hline High school graduate & $18(34.6)$ \\
\hline Some college & $11(21.2)$ \\
\hline College graduate & $6(11.5)$ \\
\hline Graduate school & $3(5.8)$ \\
\hline \multicolumn{2}{|l|}{ Income } \\
\hline Not given & $12(23.1)$ \\
\hline$<\$ 10000$ & 19 (36.5) \\
\hline$\$ 10000-\$ 24999$ & $9(17.3)$ \\
\hline$\$ 25000-\$ 49999$ & $8(15.4)$ \\
\hline$\$ 50000$ or more & $4(7.7)$ \\
\hline
\end{tabular}

${ }^{*}$ Responses do not add up to $100 \%$ as people did not respond to the item or data are missing.

report standardised coefficients. Because of the number of predictors and small sample size, we first tested each of the treatment-related factors individually. Next, we modelled only those client factors that were statistically significant (session language, employment history and $\mathrm{BTQ}-\mathrm{L} / \mathrm{F}$ ) in the previous set of analyses. To assess fit for the final model, we used comparative fit index (CFI) and standardised root mean residual (SRMR). Additional fit indices were evaluated, but did not provide additional information and were not reported. Finally, binary logistic regression was used to assess the impact of treatment-related variables on CPT treatment completion. We report unstandardised regression coefficients with their $95 \%$ CI. 3233

\section{RESULTS}

\section{Descriptive statistics}

See table 1 for sociodemographic characteristics of the sample. The mean age of the sample was $40.1 \quad(\mathrm{SD}=14.3)$ years old. Table 2 displays descriptive information for the client predictors and treatment-related variables. Table 3 details PCL-S and PHQ-9 scores across baseline 


\begin{tabular}{|c|c|}
\hline & n (\%) \\
\hline Treatment completers & $21(40.4)$ \\
\hline \multicolumn{2}{|l|}{ Language of treatment } \\
\hline English only & $35(67.3)$ \\
\hline Spanish only & $17(32.7)$ \\
\hline \multicolumn{2}{|c|}{ Employment history over the last 3 years } \\
\hline Virtually all of the time & $13(25.0)$ \\
\hline \multirow[t]{2}{*}{ Less than all of the time } & $35(67.3)$ \\
\hline & Mean (SD) range \\
\hline BTQ-L/F subscale & $4.6(4.25) 0-16$ \\
\hline BTQ-S/D subscale & $9.7(7.14) 0-24$ \\
\hline BTQ-P/S subscale & $2.8(2.76) 0-11$ \\
\hline MQLI & $4.4(1.82) 1.3-8.0$ \\
\hline Weeks in study & $9.4(3.64) 4-14$ \\
\hline $\begin{array}{l}\text { Sessions with repeated CPT } \\
\text { content }\end{array}$ & 1.5 (1.57) 0-7 \\
\hline $\begin{array}{l}\text { Dose of CPT ( } \% \text { of } 12 \\
\text { sessions possible) }\end{array}$ & $63.9(27.40) 25.0-100.0$ \\
\hline Frequency of sessions & 11.3 (3.95) 5.3-25.5 \\
\hline Consistency of sessions & $9.2(6.97) 0-32.2$ \\
\hline
\end{tabular}

Frequency of sessions was measured as the mean number of days between sessions. Consistency of sessions was measured as the SD of the number of days between sessions. Treatment completion was defined as having completed 12 CPT sessions or as determined by the treating clinician's clinical judgement. BTQ, Barriers to Treatment Questionnaire; CPT, cognitive processing therapy; L/F, logistical and financial barriers; MQLI, Multicultural Quality of Life Index; P/S, treatment perception and satisfaction barriers; S/D, stigma, shame and discrimination barriers.

and nine CPT sessions. Preliminary analyses evaluated whether demographic characteristics were related to any of the study's dependent measures. Session language predicted the number of sessions with repeated CPT content, $t(50)=-2.61, p=0.016$. Also, employment history was marginally related to the number of sessions with repeated CPT content, $t(149673)=1.83, p=0.067$. Session language and employment history were thus included in subsequent analyses.

\section{Research aim 1}

Table 4 displays the regression results assessing the predictive value of the client characteristics (MQLI scores and the three BTQ subscales) on five treatment engagementrelated variables (number of weeks in the study, number of sessions with repeated CPT interventions, dose of CPT, frequency of sessions and consistency of sessions) controlling for session language and clients' employment histories. Four significant effects were found. There were two significant predictors of the number of sessions with repeated CPT content. First, those with high MQLI scores repeated fewer CPT session content compared with those with lower MQLI scores $(\beta=-0.3, p=0.04)$. Those who received treatment in Spanish repeated more session content $(\beta=1.4$ sessions, $p=0.003)$ compared with those who received CPT in English. We identified significant session language by BTQ-L/F (logistical and financial) subscale interactions for both (1) frequency of sessions and (2) consistency of sessions. For both dependent measures, one's score on the BTQ-L/F scale was not related to differences in the frequency or consistency of sessions (all $r \approx 0.01, p>0.848$ ). However, among those receiving treatment in Spanish, higher BTQ-L/F scores were related to more days between sessions $(r=0.62$, $p=0.009)$ and greater variability in session attendance $(r=0.57, p=0.027)$.

\section{Research aim 2}

The second research goal focused on determining the impact of two sets of predictors on the three treatment outcomes of (1) PCL-S trajectories from baseline to session 9, (2) PHQ-9 trajectories from baseline to session 9, and (3) the dichotomous indicator of treatment completion status. The first set of predictors were the five treatment engagement-related factors from the previous analyses. The second set of predictors were client-level variables identified as important in the previous analyses. Table 5 summarises the results from the latent growth curve models which separately modelled the impact of each of the five treatment engagement-related factors on PCL-S

Table 3 Descriptive statistics (mean, SD, percent of scores missing) for therapeutic outcomes by study week

\begin{tabular}{|c|c|c|c|c|c|c|c|c|c|c|}
\hline & \multicolumn{10}{|c|}{ Cognitive processing therapy week number } \\
\hline & Baseline & 1 & 2 & 3 & 4 & 5 & 6 & 7 & 8 & 9 \\
\hline PCL-S & $\begin{array}{l}61.3 \\
(12.37) \\
17.3 \%\end{array}$ & $\begin{array}{l}57.9 \\
(12.44) \\
13.5 \%\end{array}$ & $\begin{array}{l}57.1 \\
(11.71) \\
17.3 \%\end{array}$ & $\begin{array}{l}56.7 \\
(12.59) \\
17.3 \%\end{array}$ & $\begin{array}{l}50.2 \\
(14.09) \\
25.0 \%\end{array}$ & $\begin{array}{l}52.2 \\
(15.02) \\
30.8 \%\end{array}$ & $\begin{array}{l}50.3 \\
(15.77) \\
34.6 \%\end{array}$ & $\begin{array}{l}50.9 \\
(16.29) \\
42.3 \%\end{array}$ & $\begin{array}{l}47.1 \\
(16.02) \\
50.0 \%\end{array}$ & $\begin{array}{l}42.8 \\
(16.45) \\
53.8 \%\end{array}$ \\
\hline PHQ-9 & $\begin{array}{l}15.9 \\
(5.98) \\
13.5 \%\end{array}$ & $\begin{array}{l}16.2 \\
(5.67) \\
23.1 \%\end{array}$ & $\begin{array}{l}15.8 \\
(5.40) \\
21.2 \%\end{array}$ & $\begin{array}{l}14.7 \\
(5.53) \\
25.0 \%\end{array}$ & $\begin{array}{l}13.4 \\
(6.28) \\
28.8 \%\end{array}$ & $\begin{array}{l}13.3 \\
(6.53) \\
38.5 \%\end{array}$ & $\begin{array}{l}12.4 \\
(6.45) \\
44.2 \%\end{array}$ & $\begin{array}{l}12.3 \\
(6.79) \\
50.0 \%\end{array}$ & $\begin{array}{l}12.3 \\
(7.74) \\
53.8 \%\end{array}$ & $\begin{array}{l}9.9 \\
(7.23) \\
57.7 \%\end{array}$ \\
\hline
\end{tabular}

Data reported are raw scores.

PCL-S, Post-Traumatic Stress Disorder Checklist-Specific version; PHQ-9, Patient Health Questionnaire 9. 
Table 4 Results from regression analyses for client-related predictors of treatment engagement-related factors

\begin{tabular}{|c|c|c|c|c|c|}
\hline & $\begin{array}{l}\text { Number of weeks } \\
\text { in study }\end{array}$ & $\begin{array}{l}\text { Number of } \\
\text { sessions with } \\
\text { repeated content }\end{array}$ & Dose of CPT & $\begin{array}{l}\text { Frequency of } \\
\text { sessions }\end{array}$ & $\begin{array}{l}\text { Consistency of } \\
\text { sessions }\end{array}$ \\
\hline & $\begin{array}{l}\text { Estimate } \\
(95 \% \mathrm{Cl})\end{array}$ & $\begin{array}{l}\text { Estimate } \\
(95 \% \mathrm{Cl})\end{array}$ & $\begin{array}{l}\text { Estimate } \\
(95 \% \mathrm{Cl})\end{array}$ & $\begin{array}{l}\text { Estimate } \\
(95 \% \mathrm{Cl})\end{array}$ & $\begin{array}{l}\text { Estimate } \\
(95 \% \mathrm{Cl})\end{array}$ \\
\hline \multicolumn{6}{|l|}{ Predictors } \\
\hline Session language & $\begin{array}{l}0.95 \\
(-1.48 \text { to } 3.37)\end{array}$ & $\begin{array}{l}1.42^{\star \star} \\
(0.50 \text { to } 2.35)\end{array}$ & $\begin{array}{l}-3.39 \\
(-21.12 \text { to } 14.33)\end{array}$ & $\begin{array}{l}1.14 \\
(-1.33 \text { to } 3.60)\end{array}$ & $\begin{array}{l}2.21 \\
(-2.21 \text { to } 6.62)\end{array}$ \\
\hline Employment history & $\begin{array}{l}0.74 \\
(-2.14 \text { to } 3.63)\end{array}$ & $\begin{array}{l}-0.90 \\
(-2.00 \text { to } 0.20)\end{array}$ & $\begin{array}{l}13.33 \\
(-7.97 \text { to } 34.62)\end{array}$ & $\begin{array}{l}0.52 \\
(-2.38 \text { to } 3.41)\end{array}$ & $\begin{array}{l}0.74 \\
(-4.41 \text { to } 5.88)\end{array}$ \\
\hline MQLI & $\begin{array}{l}-0.43 \\
(-1.12 \text { to } 0.26)\end{array}$ & $\begin{array}{l}-0.28^{\star} \\
(-0.55 \text { to } 0.01)\end{array}$ & $\begin{array}{l}-1.11 \\
(-6.06 \text { to } 3.84)\end{array}$ & $\begin{array}{l}-0.46 \\
(-1.21 \text { to } 0.28)\end{array}$ & $\begin{array}{l}-0.69 \\
(-1.98 \text { to } 0.60)\end{array}$ \\
\hline BTQ-L/F subscale & $\begin{array}{l}-0.19 \\
(-1.02 \text { to } 0.64)\end{array}$ & $\begin{array}{l}0.19 \\
(-0.13 \text { to } 0.50)\end{array}$ & $\begin{array}{l}-3.28 \\
(-9.39 \text { to } 2.84)\end{array}$ & $\begin{array}{l}-0.71 \\
(-1.53 \text { to } 0.12)\end{array}$ & $\begin{array}{l}-1.04 \\
(-2.53 \text { to } 0.45)\end{array}$ \\
\hline BTQ-S/D subscale & $\begin{array}{l}0.01 \\
(-0.17 \text { to } 0.19)\end{array}$ & $\begin{array}{l}-0.01 \\
(-0.08 \text { to } 0.06)\end{array}$ & $\begin{array}{l}0.31 \\
(-1.03 \text { to } 1.65)\end{array}$ & $\begin{array}{l}0.01 \\
(-0.17 \text { to } 0.19)\end{array}$ & $\begin{array}{l}-0.02 \\
(-0.34 \text { to } 0.30)\end{array}$ \\
\hline BTQ-P/S subscale & $\begin{array}{l}-0.02 \\
(-0.45 \text { to } 0.41)\end{array}$ & $\begin{array}{l}0.07 \\
(-0.10 \text { to } 0.23)\end{array}$ & $\begin{array}{l}-0.84 \\
(-4.00 \text { to } 2.31)\end{array}$ & $\begin{array}{l}0.11 \\
(-0.32 \text { to } 0.54)\end{array}$ & $\begin{array}{l}0.20 \\
(-0.57 \text { to } 0.97)\end{array}$ \\
\hline $\begin{array}{l}\text { BTQ-L/F } \times \text { session } \\
\text { language interaction }\end{array}$ & $\begin{array}{l}-0.01 \\
(-0.55 \text { to } 0.53)\end{array}$ & $\begin{array}{l}-0.13 \\
(-0.33 \text { to } 0.08)\end{array}$ & $\begin{array}{l}0.99 \\
(-2.95 \text { to } 4.93)\end{array}$ & $\begin{array}{l}0.65^{\star} \\
(0.11 \text { to } 1.19)\end{array}$ & $\begin{array}{l}1.02^{*} \\
(0.03 \text { to } 2.01)\end{array}$ \\
\hline
\end{tabular}

Bolded results are statistically significant. Estimate=unstandardised regression coefficient. Frequency of sessions was measured as the mean number of days between sessions. Consistency of sessions was measured as the SD of the number of days between sessions. Session language: $0=$ English, $1=$ Spanish. Employment history: $0=$ all other, $1=$ employed virtually all of the time in the last 3 years. ${ }^{*} \mathrm{p}<0.05 ;{ }^{* *} \mathrm{p}<0.01$.

BTQ, Barriers to Treatment Questionnaire; CPT, cognitive processing therapy; L/F, logistical and financial barriers; MQLI, Multicultural Quality of Life Index; P/S, treatment perception and satisfaction barriers; S/D, stigma, shame and discrimination barriers.

growth factors (ie, intercept, linear slope and quadratic terms). No statistically significant effects were found.

Table 6 displays the latent growth curve modelling results determining the impact of client characteristics on PCL-S trajectories. All variables were entered into the same model and the model fit the data well; CFI=1.00 and $\mathrm{SRMR}=0.07$, especially given the small sample size. Only one significant effect of the predictors of the PCL-S growth factors was identified. Higher baseline BTQ-L/F scores predicted a deceleration in changes in PCL-S over time.

Next, a similar set of latent growth curve models were developed for PHQ-9 scores. Table 7 displays the results from the latent growth curve models which tested the effects of each of the treatment-related factors on the PHQ-9 trajectories. While the CFI fit values indicated good model, the SRMR values for all models indicated poor fit. SRMR values are impacted more strongly by the

Table 5 Standardised parameter estimates from latent growth curve models individually testing the effects of each treatment engagement factor on changes in PCL-S scores over time

Growth factors for PCL-S scores

Direct effects of intercept Direct effects of treatment Direct effects of treatment Treatment engagement on treatment engagement engagement factors on engagement factors on factors factors linear slope

Model fit quadratic term CFI/SRMR

\begin{tabular}{|c|c|c|c|c|}
\hline $\begin{array}{l}\text { Number of weeks in } \\
\text { study }\end{array}$ & $\beta=-0.07$ & $\beta=0.11$ & $\beta=-0.05$ & $1.00 / 0.08$ \\
\hline $\begin{array}{l}\text { Number of CPT sessions } \\
\text { with repeated content }\end{array}$ & $\beta=0.12$ & $\beta=-0.07$ & $\beta=0.001$ & $1.00 / 0.08$ \\
\hline Dose of CPT & $\beta=-0.13$ & $\beta=0.16$ & $\beta=-0.08$ & $1.00 / 0.08$ \\
\hline Frequency of sessions & $\beta=0.02$ & $\beta=0.05$ & $\beta=0.03$ & $0.99 / 0.09$ \\
\hline Consistency of sessions & $\beta=0.06$ & $\beta=0.11$ & $\beta=0.01$ & $0.98 / 0.09$ \\
\hline
\end{tabular}

Frequency of sessions was measured as the mean number of days between sessions. Consistency of sessions was measured as the SD of the number of days between sessions.

$\beta$, standardised parameter estimates; CFI, comparative fit index; CPT, cognitive processing therapy; PCL-S, Post-Traumatic Stress Disorder Checklist-Specific version; SRMR, standardised root mean residual. 
Table 6 Standardised parameter estimates from the final latent growth curve model testing the effects of the treatment engagement factors on changes in PCL-S scores over time

\begin{tabular}{llll}
\hline & \multicolumn{2}{l}{ Growth factors for PCL-S scores } & \\
\cline { 2 - 4 } Treatment engagement factors & $\begin{array}{l}\text { Direct effects of intercept } \\
\text { factors }\end{array}$ & $\begin{array}{l}\text { Direct effects of treatment } \\
\text { engagement factors on } \\
\text { linear slope }\end{array}$ & $\begin{array}{l}\text { Direct effects of treatment } \\
\text { engagement factors on } \\
\text { quadratic term }\end{array}$ \\
\hline Session language & $\beta=-0.20$ & $\beta=-0.15$ & $\beta=0.31$ \\
BTQ-L/F subscale & $\beta=0.22$ & $\beta=0.23$ & $\boldsymbol{\beta}=-\mathbf{0 . 6 2 ^ { \star }}$ \\
Employment history & $\beta=-0.09$ & $\beta=0.33$ & $\beta=-0.09$ \\
\hline
\end{tabular}

Bolded results are statistically significant.

${ }^{*} \mathrm{p}<0.05$.

BTQ, Barriers to Treatment Questionnaire; L/F, logistical and financial barriers; PCL-S, Post-Traumatic Stress Disorder Checklist-Specific version.

small sample size. Results were not interpreted for this set of models.

Next, the effects of client characteristics on the PHQ-9 trajectories were modelled (table 8). The model fit indices were mixed with CFI (1.00) indicating good model fit and SRMR (0.11) indicating poor model fit. Again, this is likely related to the small sample size. No significant effects were identified.

The final set of analyses assessed the impacts of the treatment-related variables and the client characteristics on completing CPT treatment. The upper half of table 9 summarises the effects of the treatment-related factors on CPT completion. Those who repeated more CPT session content were significantly more likely to complete CPT, $\mathrm{OR}=1.84, p=0.037$. The lower half of table 9 details the effects of client characteristics on CPT completion. No significant predictors of CPT completion, as a binary variable, were identified.

\section{DISCUSSION}

\section{Main findings}

The current study focused on exploring client-level characteristics that extend beyond demographics in predicting treatment outcome and dropout in PTSD treatment in a diverse community health centre. In addition, the study also assessed client-level predictors of treatment engagement moderators in community samples, including frequency and consistency of attendance, number of weeks in treatment, repetition of session content and dose of PTSD treatment.

The results of the study show language to be a significant predictor of treatment engagement moderators. Spanish-speaking clients were more likely to repeat session content, with a tendency to repeat 1.4 sessions more than English speakers, over the course of treatment. The results are consistent within the context of the Spanish-speaking Latino literature, which has found that bilingual providers face multiple barriers when delivering treatment in Spanish, including difficulties translating technical vocabulary, which can result in communication delays (eg, ref 35). Furthermore, the logistical and financial barriers that were present at the beginning of treatment continued to be a barrier to treatment attendance for Spanish-speaking clients. Spanish speakers who endorsed more logistical and financial difficulties at the beginning of treatment were more likely to

Table 7 Standardised parameter estimates from latent growth curve models individually testing the effects of each treatment engagement factor on changes in PHQ-9 scores over time

\begin{tabular}{|c|c|c|c|c|}
\hline \multirow[b]{2}{*}{$\begin{array}{l}\text { Treatment engagement } \\
\text { factors }\end{array}$} & \multicolumn{3}{|c|}{ Growth factors for PHQ-9 scores } & \multirow[b]{2}{*}{$\begin{array}{l}\text { Model fit } \\
\text { CFI/SRMR }\end{array}$} \\
\hline & $\begin{array}{l}\text { Direct effects of } \\
\text { intercept on treatment } \\
\text { engagement factors }\end{array}$ & $\begin{array}{l}\text { Direct effects of } \\
\text { treatment engagement } \\
\text { factors on linear slope }\end{array}$ & $\begin{array}{l}\text { Direct effects of treatment } \\
\text { engagement factors on } \\
\text { quadratic term }\end{array}$ & \\
\hline Number of weeks in study & $\beta=0.10$ & $\beta=-0.49$ & $\beta=0.89$ & $1.00 / 0.16$ \\
\hline $\begin{array}{l}\text { Number of CPT sessions } \\
\text { with repeated content }\end{array}$ & $\beta=0.12$ & $\beta=-0.09$ & $\beta=0.19$ & $0.97 / 0.16$ \\
\hline Dose of CPT & $\beta=0.07$ & $\beta=-0.45$ & $\beta=0.87$ & $1.00 / 0.15$ \\
\hline Frequency of sessions & $\beta=0.07$ & $\beta=-0.11$ & $\beta=0.33$ & $1.00 / 0.16$ \\
\hline Consistency of sessions & $\beta=0.21$ & $\beta=-0.51$ & $\beta=0.84$ & $1.00 / 0.17$ \\
\hline
\end{tabular}

Frequency of sessions was measured as the mean number of days between sessions. Consistency of sessions was measured as the SD of the number of days between sessions.

$\beta$, standardised parameter estimates; CFI, comparative fit index; CPT, cognitive processing therapy; PHQ-9, Patient Health Questionnaire 9; SRMR, standardised root mean residual. 
Table 8 Standardised parameter estimates from the final latent growth curve model testing the effects of the treatment factors on changes in PHQ-9 scores over time

\begin{tabular}{llll}
\hline & \multicolumn{2}{l}{ Growth factors for PHQ-9 scores } \\
\cline { 2 - 4 } Treatment factors & $\begin{array}{l}\text { Direct effects of intercept } \\
\text { on treatment factors }\end{array}$ & $\begin{array}{l}\text { Direct effects of treatment } \\
\text { factors on linear slope }\end{array}$ & $\begin{array}{l}\text { Direct effects of treatment } \\
\text { factors on quadratic term }\end{array}$ \\
\hline Session language & $\beta=-0.14$ & $\beta=-0.08$ & $\beta=0.08$ \\
BTQ-L/F subscale & $\beta=-0.05$ & $\beta=0.32^{*}$ & $\beta=-0.62^{*}$ \\
Employment history & $\beta=-0.04$ & $\beta=0.16$ & $\beta=-0.09$ \\
\hline
\end{tabular}

${ }^{*} 0.10<\mathrm{p}<0.05$.

$\beta$, standardised parameter estimates; BTQ, Barriers to Treatment Questionnaire; L/F, logistical and financial barriers; PHQ-9, Patient Health Questionnaire 9.

attend treatment less frequently and less consistently than English speakers. Previous literature has shown that Latinos face added problems related to transportation and fulfilling other basic needs. ${ }^{36}$ The results of this study add to this existing literature by showing the persistent impact that these added psychosocial difficulties have on Spanish-speaking clients' continued use of mental health services. The combination of the results of the current study highlights the unique challenges faced by Spanish-speaking clients. Given the significant continued logistical and financial barriers impacting this group's frequency of session attendance, it is also understandable that Spanish-speaking clients may be more likely to repeat session content than English speakers as they would need a refresher on treatment concepts. However, these differences did not impact treatment outcome overall

Table 9 Treatment engagement-related and client factors as predictors of CPT treatment completion status

\section{OR $(95 \% \mathrm{Cl})$}

\begin{tabular}{ll}
\hline $\begin{array}{l}\text { Part I. Treatment engagement } \\
\text { factors }\end{array}$ & \\
$\begin{array}{l}\text { Number of CPT sessions with } \\
\text { repeated content }\end{array}$ & $\mathbf{1 . 8 4 *}(1.04$ to 3.26$)$ \\
\hline $\begin{array}{l}\text { Frequency of sessions } \\
\text { Consistency of sessions }\end{array}$ & $0.74(0.48$ to 1.13$)$ \\
\hline $\begin{array}{l}\text { Part II. Client factors } \\
\text { Session language }\end{array}$ & 1.08 (0.85 to 1.36$)$ \\
\hline Employment history & $0.13(0.01$ to 3.43$)$ \\
\hline MQLI & $0.73(0.05$ to 10.29$)$ \\
\hline BTQ-L/F subscale & $0.77(0.40$ to 1.48$)$ \\
\hline BTQ-S/D subscale & $0.76+(0.57$ to 1.02$)$ \\
\hline BTQ-P/S subscale & $0.96(0.78$ to 1.17$)$ \\
\hline
\end{tabular}

Bolded results are statistically significant. Estimate=unstandardised regression coefficient.

${ }^{*} \mathrm{p}<0.05$.

$\dagger 0.10<\mathrm{p}<0.05$.

BTQ, Barriers to Treatment Questionnaire; CPT, cognitive processing therapy; L/F, logistical and financial barriers; MQLI, Multicultural Quality of Life Index; P/S, treatment perception and satisfaction barriers; S/D, stigma, shame and discrimination barriers. even when delivered within a low-resource community setting, which are suggestive of the robust effects of CPT as a treatment. Spanish-speaking clients were as likely as English-speaking clients to improve with CPT treatment.

The results of the study also highlight the importance of attending to various clients' pretreatment life-functioning domains. For example, quality of life level was predictive of clients' treatment engagement behaviours, with clients who reported higher quality of life pretreatment being less likely to repeat CPT session content. This may have been due to clients being more likely to attend to and hold onto treatment content if they were more satisfied with their general well-being and had fewer competing immediate priorities. Relatedly, increased baseline logistical and financial barriers to treatment decelerated client's PTSD symptom improvement over time, regardless of treatment language. Previous literature has shown that these types of barriers significantly impact treatment utilisation (eg, ref ${ }^{37}$ ). The results of the current study suggest that even if clients are able to overcome these barriers to initiate treatment, they may continue to impact clients' treatment outcome.

There were no additional client-level predictors impacting treatment outcome, dropout or timing of sessions. In terms of treatment engagement moderators impacting treatment outcome, clients who repeated more session content were more likely to complete treatment. These results are consistent with the emerging literature highlighting the importance of flexibly delivering EBTs for PTSD in community settings, including extending the total number of sessions (eg, ref 38), and modifying treatment elements to be attuned to client needs. ${ }^{29}$

Despite the fact that the effects of CPT are robust across client populations and treatment settings, it would be clinically important for clinicians treating Spanish-speaking clients in community settings to assess and possibly address the impact of logistical and financial stressors during treatment, especially as it relates to Spanishspeaking clients' treatment frequency and consistency of attendance. The clients in the current sample attended sessions more frequently but less consistently compared with other clients receiving CPT in community settings, ${ }^{16}$ which may account for the lack of differences in treatment outcome. The effects of clients' inconsistent treatment 
attendance may have been mitigated by the fact that the providers in the study were receiving 6 months of rigorous CPT consultation, which previous studies have shown impact treatment outcome. ${ }^{39}$ However, ongoing consultation and feedback is not a feasible solution in routine clinical care in community settings, where resources and clinicians' time are limited. ${ }^{40}$ Thus, it would be clinically recommended that providers assess for logistical and financial stressors at baseline and continuously monitor possible changes, with referrals for adjunctive supports as needed, as ameliorating concrete stressors may facilitate clients' frequent and consistent attendance to treatment and lead to positive treatment outcome.

\section{Limitations}

There are several limitations in the current study that should be noted. First, the small client sample size may have limited our ability to detect the impact of client-level predictors.

Future studies should continue to evaluate client characteristics beyond client demographics that relate to treatment outcome, dropout and timing of sessions. Second, the analyses did not adjust for family-wise error and should be considered exploratory. Third, the reliability for the BTQ-L/F scales was low in the sample, which could have been influenced by the small sample size, and due to most clients reporting having experienced few of these types of barriers. Despite the fact that the study sample included clients being served in an under-resourced setting, the clinic is accessible by public transportation and treatment is largely reimbursed through Medicaid, which could explain why most clients in the study sample did not endorse L/F-related barriers to treatment. Thus, future studies should include clients with a range of $\mathrm{L} / \mathrm{F}$-related difficulties. Finally, the sample in the study excludes those who attended less than three sessions, which could impact predictors of treatment dropout. It was necessary to include clients who had attended at least three sessions to have enough data points to conduct the latent growth curve models in the study.

\section{Implications}

Identification of client-level predictors of treatment engagement, outcome and dropout is essential to optimise treatment by helping identify clients with differing treatment outcomes, especially in community settings. Using data from an open trial of CPT for PTSD in a diverse community health centre, we found significant differences between Spanish and English-speaking clients in terms of repetition of sessions, and the impact of logistical and financial barriers in their frequency and consistency of treatment attendance. Assessing these types of barriers at baseline and continuing to monitor for changes during treatment can allow for clinical discussions to encourage client's treatment attendance and outcomes.

Acknowledgements The authors express their sincere gratitude to the project's research assistants and to the providers and patients who participated in the research.
Contributors SJY, SWS, DLS and LM were responsible for the conceptualisation and design of the study, and for writing all sections of the manuscript. MAM conducted the statistical analyses, interpreted the data and wrote the statistical analyses and results sections. KAP and YAS contributed to the drafting of the introduction and method sections. ADB contributed to the revisions and formatting of the manuscript in preparation for publication. All authors read, revised and approved the final manuscript.

Funding This study was funded by a grant through the National Institutes of Health (NIMH K23 MH096029-01A1) awarded to LM. Contributions of SWS to the study were partially funded by another grant through the National Institutes of Health (NIMH 1R01MH112628-01).

Competing interests None declared.

Patient consent for publication Not required.

Ethics approval All study procedures were approved by the site's institutional review board.

Provenance and peer review Commissioned; externally peer reviewed.

Data availability statement Data are available upon reasonable request.

Open access This is an open access article distributed in accordance with the Creative Commons Attribution Non Commercial (CC BY-NC 4.0) license, which permits others to distribute, remix, adapt, build upon this work non-commercially, and license their derivative works on different terms, provided the original work is properly cited, appropriate credit is given, any changes made indicated, and the use is non-commercial. See: http://creativecommons.org/licenses/by-nc/4.0/.

ORCID iD

Soo-jeong Youn http://orcid.org/0000-0002-7528-5042

\section{REFERENCES}

1 Druss BG, Hwang I, Petukhova M, et al. Impairment in role functioning in mental and chronic medical disorders in the United States: results from the National comorbidity survey replication. Mol Psychiatry 2009;14:728-37.

2 Bradley R, Greene J, Russ E, et al. A multidimensional meta-analysis of psychotherapy for PTSD. Am J Psychiatry 2005;162:214-27.

3 Hamburg MA, Collins FS. The path to personalized medicine. N Engl J Med 2010;363:301-4.

4 Rizvi SL, Vogt DS, Resick PA. Cognitive and affective predictors of treatment outcome in cognitive processing therapy and prolonged exposure for posttraumatic stress disorder. Behav Res Ther 2009;47:737-43.

5 van Minnen A, Arntz A, Keijsers GPJ. Prolonged exposure in patients with chronic PTSD: predictors of treatment outcome and dropout. Behav Res Ther 2002;40:439-57.

6 Wade D, Varker T, Kartal D, et al. Gender difference in outcomes following trauma-focused interventions for posttraumatic stress disorder: systematic review and meta-analysis. Psychol Trauma 2016;8:356-64.

7 Swift JK, Greenberg RP. Premature discontinuation in adult psychotherapy: a meta-analysis. J Consult Clin Psychol 2012;80:547-59.

8 Marques L, Eustis EH, Dixon L, et al. Delivering cognitive processing therapy in a community health setting: the influence of Latino culture and community violence on posttraumatic cognitions. Psychol Trauma 2016;8:98-106.

9 Resick PA, Monson CM, Chard KM. Cognitive processing therapy for PTSD: a comprehensive manual. New York, NY: The Guilford Press, 2016.

10 Valentine SE, Borba CPC, Dixon L, et al. Cognitive processing therapy for Spanish-speaking Latinos: a formative study of a modeldriven cultural adaptation of the manual to enhance implementation in a usual care setting. J Clin Psychol 2017;73:239-56.

11 Wright KM, Britt TW, Moore D. Impediments to mental health treatment as predictors of mental health symptoms following combat. J Trauma Stress 2014;27:535-41.

12 Øktedalen T, Hoffart A, Langkaas TF. Trauma-related shame and guilt as time-varying predictors of posttraumatic stress disorder symptoms during imagery exposure and imagery rescripting--A randomized controlled trial. Psychother Res 2015;25:518-32.

13 Jennings KS, Zinzow HM, Britt TW, et al. Correlates and reasons for mental health treatment dropout among active duty soldiers. Psychol Serv 2016;13:356-63. 
14 Schnurr PP, Hayes AF, Lunney CA, et al. Longitudinal analysis of the relationship between symptoms and quality of life in veterans treated for posttraumatic stress disorder. J Consult Clin Psychol 2006;74:707-13.

15 Ehlers A, Grey N, Wild J, et al. Implementation of cognitive therapy for PTSD in routine clinical care: effectiveness and moderators of outcome in a consecutive sample. Behav Res Ther 2013;51:742-52.

16 Gutner CA, Suvak MK, Sloan DM, et al. Does timing matter? Examining the impact of session timing on outcome. J Consult Clin Psychol 2016;84:1108-15.

17 Imel ZE, Laska K, Jakupcak M, et al. Meta-analysis of dropout in treatments for posttraumatic stress disorder. J Consult Clin Psychol 2013;81:394-404

18 DeViva JC, Sheerin CM, Southwick SM, et al. Correlates of VA mental health treatment utilization among OEF/OIF/OND veterans: resilience, stigma, social support, personality, and beliefs about treatment. Psychol Trauma 2016;8:310-8.

19 Biggs QM, Fullerton CS, McCarroll JE, et al. Early intervention for post-traumatic stress disorder, depression, and quality of life in mortuary Affairs soldiers postdeployment. Mil Med 2016;181:e1553-60.

20 Weathers FW, Litz BT, Herman DS, et al. The PTSD checklist (PCL): reliability, validity, and diagnostic utility. Proceedings of the annual convention of the International Society for traumatic stress studies. San Antonio, TX, 1993.

21 Wilkins KC, Lang AJ, Norman SB. Synthesis of the psychometric properties of the PTSD checklist (PCL) military, civilian, and specific versions. Depress Anxiety 2011;28:596-606.

22 Kroenke K, Spitzer RL. The PHQ-9: a new depression diagnostic and severity measure. Psychiatr Ann 2002;32:509-15.

23 Wulsin L, Somoza E, Heck J. The feasibility of using the Spanish PHQ-9 to screen for depression in primary care in Honduras. Prim Care Companion J Clin Psychiatry 2002;4:191-5.

24 Baader T, Molina JL, Venezian S, et al. Validación y utilidad de la encuesta PHQ-9 (Patient Health Questionnaire) en el diagnóstico de depresión en pacientes usuarios de atención primaria en Chile [Validity and utility of PHQ-9 (Patient Health Questionnaire) in the diagnosis of depression in user patients of primary care in Chile]. Rev Chil Neuro-Psiquiat 2012;50:10-22.

25 Marques L, LeBlanc NJ, Weingarden HM, et al. Barriers to treatment and service utilization in an Internet sample of individuals with obsessive-compulsive symptoms. Depress Anxiety 2010;27:470-5.
26 Mezzich JE, Cohen NL, Ruiperez MA, et al. The multicultural quality of life index: presentation and validation. J Eval Clin Pract 2011;17:357-64.

27 Ferrans CE, Powers MJ. Quality of life index: development and psychometric properties. ANS Adv Nurs Sci 1985;8:15-24.

28 Schwartz KI, Zapata-Vega MI, Mezzich JE, et al. Validation study of the multicultural quality of life index (MQLI) in a Peruvian sample. Braz J Psychiatry 2006;28:24-8.

29 Marques L, Valentine SE, Kaysen D, et al. Provider fidelity and modifications to cognitive processing therapy in a diverse community health clinic: associations with clinical change. J Consult Clin Psychol 2019;87:357-69.

30 Enders CK. Multiple imputation as a flexible tool for missing data handling in clinical research. Behav Res Ther 2017;98:4-18.

31 Lu K. Number of imputations needed to stabilize estimated treatment difference in longitudinal data analysis. Stat Methods Med Res 2017;26:674-90.

32 Muthén LK, Muthén BO. Mplus user's guide. 6th edn. Los Angeles, CA: Muthén \& Muthén, 1998-2017.

33 IBM Corp. IBM SPSS statistics for windows (version 25.0). Armonk, NY: IBM Corp, 2017.

34 Heck HR, Thomas SL, Tabata LN. Multilevel and longitudinal modeling with IBM SPSS. New York, NY: Routledge, 2010.

35 Castaño MT, Biever JL, González CG, et al. Challenges of providing mental health services in Spanish. Prof Psychol 2007;38:667-73.

36 Hernandez A, Plant EA, Sachs-Ericsson N, et al. Mental health among Hispanics and Caucasians: risk and protective factors contributing to prevalence rates of psychiatric disorders. J Anxiety Disord 2005;19:844-60.

37 Jankovic J, Vidakovic I, Matanov A, et al. Reasons for not receiving treatment in people with posttraumatic stress disorder following war. J Nerv Ment Dis 2011;199:100-5.

38 Galovski TE, Blain LM, Mott JM, et al. Manualized therapy for PTSD: flexing the structure of cognitive processing therapy. J Consult Clin Psychol 2012;80:968-81.

39 Monson CM, Shields N, Suvak MK, et al. A randomized controlled effectiveness trial of training strategies in cognitive processing therapy for posttraumatic stress disorder: impact on patient outcomes. Behav Res Ther 2018;110:31-40.

40 Ruzek Jl, Rosen RC. Disseminating evidence-based treatments for PTSD in organizational settings: a high priority focus area. Behav Res Ther 2009;47:980-9.

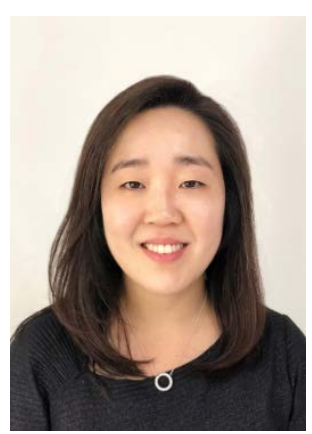

Dr. Soo Jeong Youn, Ph.D., completed her Ph.D. in Clinical Psychology at Pennsylvania State University and her clinical predoctoral internship at Massachusetts Mental Health Center, Beth Israel Deaconess Medical Center/Harvard Medical School. She completed her postdoctoral fellowship at Massachusetts General Hospital. She is currently an instructor in Psychiatry at Harvard Medical School and a Psychologist at Community Psychiatry Program for Research in Implementation and Dissemination of Evidence-Based Treatments (PRIDE) at Massachusetts General Hospital. She has extensive research conducting community-based participatory research and psychotherapy process and outcome research studies that synergistically combine clinical and scientific goals to address mental health disparities. Her clinical and research interests include implementing evidence-based practices for a variety of behavioral health disorders for underserved population in under-resourced settings. 